\title{
An Article on Growth of Smart Beta Fund Investment in Indian Financial Market
}

\author{
${ }^{*}$ Charmy Thacker \\ Assistant lecturer, Sanskar Institute of Management and IT, Bhuj - Kutch
}

\begin{abstract}
In 21st century people want each and every gadget and tool to be smart So do they need some smart investment strategies. This article is all about smart beta investment strategies which is combination of both active and passive management strategies. It also Focuses on factors, types growth, pros and cons of Smart Beta Funds. Main aim here is to clarify the concept of Smart beta and how it has been adapted in India.
\end{abstract}

Keywords: Smart Beta, ETF [Exchange Traded Fund], Factors, V alue

\section{Article Publication}

Published Online: 15-Dec-2021

*Author's Correspondence

8 Charmy Thacker

8 Assistant lecturer, Sanskar Institute of Management and IT, Bhuj Kutch

$\triangle$ charmythacker81[at]gmail.com C 2021The Authors. Published by RESEARCH REVIEW International Journal of Multidisciplinary. This is an open access article under the CC BY-

NC-ND license (c)

(https://creativecommons.org/licenses/ by-nc-nd/4.0/)

\section{Introduction}

Smart beta refers to a set of investment strategies which includes the use of alternative index construction rules compares to traditional market strategies. Smart beta is mainly used for portfolio maximization and diversification. There is no such investment as smart or dumb it's just a strategy to increase risk adjusted return. The main aim of smart beta is to just lower the Cost, increase the diversification and still insure a good amount of return. It also aims at lowering the cost compares to the traditional market. It is applicable to equity, fixed income, commodities and multi asset classes.

Smart beta strategies don't follow or track standard indices such as S \& P 500 Or Nasdaq 100 Index rather it focuses on those areas of market that provides an opportunity. So basically, smart beta fund helps to diversify one's portfolio. As smart beta fund involves both active and passive fund management investor needs to be more careful.

\section{Types of Smart Beta Fund strategies}

- Equally weighted: It equally weights all the factors and holdings.

- Fundamentally weighted: Here top companies are selected on the basis of some the factors such as earning, revenue, profit dividend etc.

- Factor-based: In this companies are selected based on some specific factors like balance sheet, underpriced etc.

- Low volatility: In this companies with low price variations are selected. 
Objectives

- To get Awareness about smart beta fund types and strategies.

- To know how smart fund strategies are working.

- To know the risk factor in smart beta fund strategies.

\section{Literature review}

In the area where people want Smart phones and many other smart tools so do they want smart investment strategies. So Smart Beta is also called ETF 2.0 and it was first used by one consulting firm Towers Watson in 1970.

Smart beta was mainly highlighted at the time of financial crises in year 2008 when market was so volatile. That time investors were in need of some strategies which minimize the risk with diversified portfolio and increased as well as adjusted returns.

So smart beta ETF involves active and passive fund management it means it considers standard index as well consider some the factors such as quality, value, high dividend etc.

In 2003 In US Equal weight smart ETF Was lunched. It was started in US with \$74 billion in 2006 and increased to \$504Billion till 2017.

If we talk about India then here Smart beta fund are still under attention zone. we do have 9 smart beta funds. It may create a great future investment scenario depending on how investors are adapting the strategies.

List of the top smart beta funds that are currently available to invest in.

\begin{tabular}{|l|c|c|}
\hline \multicolumn{1}{|c|}{ Funds } & AUM (In Rs Cr) & Expense Ratio (\%) \\
\hline ICICI Prudential Nifty Low Vol 30 ETF & 675 & 0.42 \\
\hline SBI-ETF Quality & 29 & 0.50 \\
\hline CICI Prudential Alpha Low Vol 30 ETF & 129 & 0.41 \\
\hline Nippon India Nifty 50 Value 20 Index Fund & 59 & 0.80 \\
\hline ICICI Prudential Nifty Low Vol 30 ETF & 675 & 0.42 \\
\hline SBI-ETF Quality & 29 & 0.50 \\
\hline UTI Nifty200 Momentum 30 Index Fund & 714 & 0.90 \\
\hline
\end{tabular}

(Source: https://freefincal.com/list-of-factor-based-etfs-index-funds-in-india/)

\section{Analysis of Growth of Smart beta fund Strategies}

As discussed above In India we do Have 9 Smart beta funds. Smart beta funds mainly allocate the funds on each stock based on Factors So Lets First See Smart beta factors.

1. Momentum: It refers to stock with continuous high growth or continuous low-price growth.

2. Value: It means consider stock with low price as they can perform better than one with high price.

3. Small Company: According to this small company may outperform big or large companies.

4. Quality: here low-quality companies can perform better than high quality.

If we consider Indian then here Smart beta funds mostly based on one factor. 


\section{Growth of Smart Beta Fund investment}

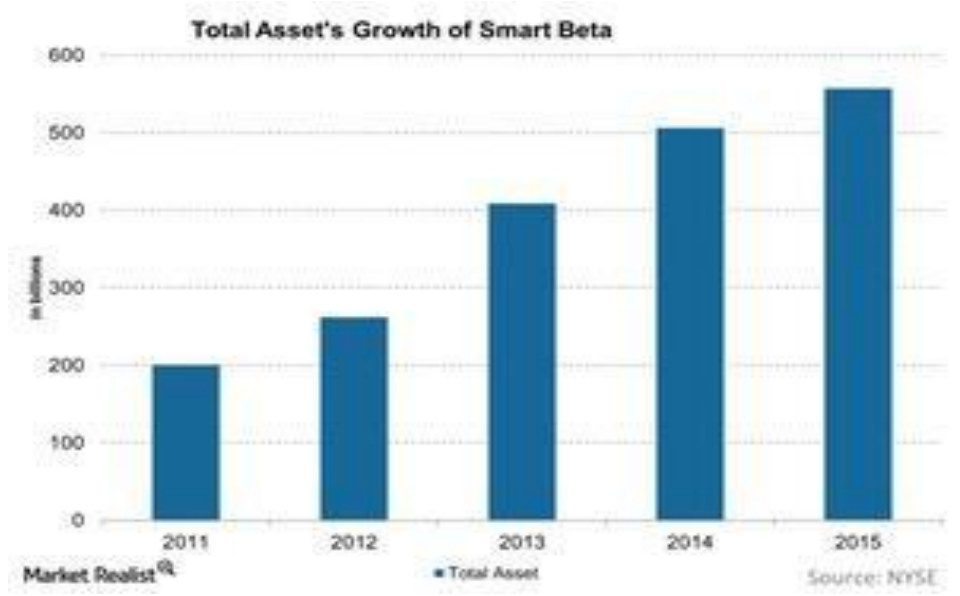

From The Above Graph we can see that Smart beta fund strategies has been increasingly adapted from the year 2012 To 2015. Within the span of 5 years, it has grown 3 times. Initially it was accepted hugely by foreign countries but gradually in India investors are also adapting this smart strategy of investing by using different factors and methods.

\section{Pros and Cons of Smart Beta fund}

\section{Pros}

- Smart beta funds are diversified funds with lower fees.

- It also allows for flexibility in selecting holdings.

- As it involves both active and passive ways it does considers other alternatives.

- It helps to avoid stock overlays.

\section{Cons}

- It may lead to difficult buying and selling.

- There may arise low Trading volume.

- It can be expensive as stocks have to be bought and sold.

- It has higher fees than passively managed funds.

\section{Risk Associated with Smart Beta Funds}

- Question may arise is it really smart to invest in smart beta funds??? Risk and return move parallel.

- Price of Smart beta fund can vary from Fund's Value.

- Here investor may face difficulty to sell or Exit position.

\section{Conclusion}

At the end smart beta funds can be a good replacement for poorly managed active funds. If you want to invest in factor funds then diversification among this factor is important So investor can have consistent diversified active equity funds and then invest in smart beta for extra returns. It provides Risk adjusted rate. If investor wants diversification, adjusted extra return and lower fees then he should go for smart beta strategies. Smart Beta ETF 2.0 has been widely used in US Market and we can hope for its bright future in India as well.

\section{References}

1. https://zerodha.com/varsity/chapter/smart-beta-funds/

2. https://jii.pm-research.com/content/4/3/15.abstract

3. https://papers.ssrn.com/sol3/papers.cfm?abstract id $=2594941$ 